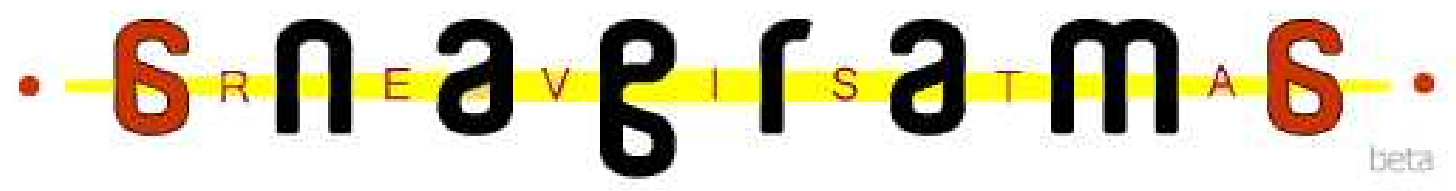

\section{Análise Semiótica Aplicada ao Estudo de \\ Audiouisualidades nas mídias}

\section{Ewerton Luis Faverzani Figueiredo ${ }^{7}$}

\section{Resumo}

O seguinte estudo aborda temas que envolvem métodos de análise semióticos sumamente aplicados à análise do audiovisual em todos os seus aspectos. Deste modo, pôde-se descrever a contribuição conceitual de autores como Lèvy, Parente, Santiago, Benjamim, Flusser, Stiegler e Felinto. Em decorrência disso, os conceitos descritos discutem tópicos como "Os quatro modos de ser" de Pierre Lèvy e "O virtual, auto-referente e tecno(onto)lógico" de André Parente; "Elementos sensível/inteligível e significado/significante" segundo análise de Silviano Santiago; "A reprodutibilidade técnica" segundo Walter Benjamim; "Códigos, linha e superfície" sob a perspectiva de Vilém Flusser; "As categorias cenopitagóricas" de Pierce; "Simulações de programas digitais" na visão de Bernard Stiegler e por fim "O imaginário humano sobre as novas tecnologias" de Erick Felinto. Busca-se com essas referências resenhar descritivamente pontos mais significantes e que merecem maior ênfase no que se infere aos autores estudados. E com isso concentrar esforços para a elaboração de um trabalho mais consistente.

Palauras-chave: Semiótica; Mídias audiovisuais; Comunicação.

${ }^{1}$ Graduado em Comunicação Social - Relações Públicas pela UFSM. E-mail: ewertonfaverzani@gmail.com. 


\section{Os quatro modos de ser de Pierre Lèuy e o virtual, auto-referente e tecno(onto)lógico de André Parente}

O livro "O que é o virtual?" de Pierre Lèvy, trata da relação existente entre o real e o possível, o atual e o virtual. Como o próprio autor explica levando em conta as contribuições de Gilles Deleuze, o possível como uma realização futura sem mudanças na sua determinação e natureza. Sendo assim, um real fantasmático, latente. E ainda diz mais, no momento em que trata o possível exatamente como o real, em tom de igualdade, embora dote um importante aspecto de diferenciação entre ambos ao dizer que o possível em função do real, é inexistente.

Este autor analisa a questão virtual/atual, afirmando que o virtual se opõe ao atual, sento aquele um complexo problemático de forças que acompanha uma situação, um acontecimento, um objeto ou uma entidade qualquer, e que chama um processo de resolução: a atualização. $\mathrm{O}$ atual para Lèvy carrega e produz a uma entidade qualquer um acontecimento, reorganizando-se e sucedendo-se a receber interpretações variadas. Já segundo este autor, o virtual constitui a entidade, os acontecimentos inerentes a um ser, sua problemática, seus nós de tensões, coerções e de projetos que o animam, inclusive as questões que o movem sendo uma parte essencial de sua determinação.

Lèvy trás ainda o conceito que envolve os quatro modos de ser: real, possível, atual, virtual remetendo para quatro passagens desses expoentes de análise. Assim, segundo o autor a transformação do real em realização é definida por uma eleição, por uma queda de potencial e isto se dá na ordem da seleção ocasionando uma causalidade em nível material e uma temporalidade no mecanismo de realização. O possível é transformado em potencialização e define com isso a produção de recursos da ordem da seleção, gerando uma causalidade formal numa temporalidade focada no trabalho. $\mathrm{O}$ atual sofre transformação em nível de atualização que opera na resolução de problemas em sua definição numa ordem de criação. Sua causalidade é eficiente porque é um processo dado na temporalidade. O virtual sofre transformação e passa a virtualização. A partir daí sua definição circunda em torno da invenção de problemas da ordem da criação. Criação esta envolvendo uma causalidade final, uma situação de temporalidade no sentido de eternidade.

Em relação a isso se pode fazer referência à obra de André Parente intitulada " $O$ virtual e o hipertextual", onde o autor enfatiza a idéia de imagem virtual como auto- 
referente. Segundo este autor, hoje em dia, existe pelo menos três diferentes concepções do que seja virtual. Uma primeira tendência (expressa nos trabalhos de Edmond Couchot, Jean-Paul Fargier e Arlindo Machado, entre outros) quer nos fazer crer que o surgimento de uma tecnologia do virtual é capaz de explicar o fato de a imagem, na cultura contemporânea, ter se tornado auto-referente e, por isso, ter rompido com os modelos de representação.

Uma segunda tendência (cujas figuras de Poá são Baudrillard e Virillo) toma o virtual tecnológico como um sintoma e não como uma causa de mutações culturais. Para além deste ou daquele meio (cinema, televisão, vídeo...) as imagens contemporâneas são virtuais, auto-referentes, ou seja, a imagem pós-moderna é um significante sem referente social.

Uma terceira tendência (presente nos textos de Gilles Deleuze, Félix Guattari, Pierre Lèvy, Jean-Louis Weissberg, entre outros) afirma o virtual como uma função da imaginação criadora, fruto de agenciamentos os mais variados entre a arte, a tecnologia e a ciência, capazes de criar novas condições de modelagem do sujeito e do mundo.

Parente nesta obra fala ainda sobre o virtual tecno(onto)lógico que através das contribuições de Edmond Couchot no livro que leva o título de "Images: de l'optique au numérique" encontra os principais argumentos a respeito da primeira tendência que parte de uma determinação puramente técnica do virtual para dela tentar criar os princípios de uma ontologia da imagem de síntese, o virtual, resultado de uma evolução das técnicas de figuração, leva a uma ruptura com os modelos de representação.

Deste modo, essas tendências se dividem em dois tópicos de esclarecimento. De um lado, teríamos os modelos óticos de figuração, que tiveram origem com a perspectiva centro-linear renascentista, com seus perspectivadores, e em particular a câmara obscura, protótipo dos modelos fotomecânicos. Estes modelos produzem imagens (pintura, fotografia, cinema, vídeo) como duplas do real, as quais dependem de uma fé perceptiva de uma aderência ao mundo real como lugar das coisas e dos fenômenos. Segundo Couchot, a conquista do instantâneo fotográfico, do movimento cinematográfico, da simultaneidade da transmissão televisiva, operou uma aproximação cada vez maior do real e da imagem com o seu duplo.

Do outro lado, teríamos os modelos numéricos e digitais responsáveis pelas imagens de síntese, imagens e realidades virtuais, auto-referentes. Se alguma coisa 
preexiste à imagem de síntese, é o programa, isto é, os números (algoritmos): "a imagem não mais representa o real, ela o simula".

\section{Códigos, linha e superfície sob a perspectiua de Vilém Flusser}

O livro "O mundo codificado" de Vilém Flusser trás a tona algumas reflexões importantes sobre a questão dos símbolos organizados em códigos remetendo para uma ruptura com a primeira natureza, sozinhos e incomunicáveis para uma segunda natureza dos códigos e símbolos que os constituem. Para o autor, o objetivo do mundo codificado que nos circunda é que esqueçamos que ele consiste num tecido artificial que esconde uma natureza sem significado, sem sentido, por ele representada. O objetivo da comunicação humana é nos fazer esquecer desse contexto insignificante em que nos encontramos completamente sozinhos e "incomunicáveis" -, ou seja, é nos fazer esquecer desse mundo em que ocupamos uma cela solitária e em que somos condenados à morte - o mundo da natureza.

Para Flusser a comunicação humana tece o véu do mundo codificado, o véu da arte, da ciência, da filosofia e da religião, ao redor de nós, e o tece com pontos cada vez mais apertados, para que esqueçamos nossa própria solidão e morte, e também a morte daqueles que amamos. Em suma, o homem comunica-se com os outros; é um "animal apolítico", não pelo fato de ser um animal social, mas sim porque é um animal solitário, incapaz de viver na solidão.

Deste modo o autor remete ainda para a análise da teoria da comunicação no momento em que afirma que ela se ocupa com o tecido artificial do deixar-se esquecer da solidão, e por causa disso é uma "humanity”. Na verdade, aqui não é o lugar de se falar da diferença entre "natureza", por um lado, e "arte" (ou "cultura", ou "espírito"), por outro. Mas a conseqüência metodológica da afirmação de que a teoria da comunicação não é uma ciência natural que tem que ser abordada. E diz ainda que parece que uma coisa se torna "natureza" na medida em que é explicada, e se torna "espírito" na medida em que alguém decide interpretá-la. Deste modo, ainda nesse pensamento, a teoria da comunicação será entendida como uma disciplina interpretativa (diferentemente, por exemplo, da "teoria da informação" ou da "informática"), e a comunicação humana será abordada como um fenômeno significativo e a ser interpretado.

Assim, para suprir a falta de sentido da comunicação, a comunicação humana busca alcançá-la na medida em que estabelece um mundo codificado, ou seja, um mundo 
construído a partir de símbolos ordenados, no qual se represam a questão dos códigos e seus símbolos.

Mais adiante o autor comenta sobre a questão de linha e superfície dizendo que as superfícies adquirem cada vez mais importância no nosso dia-a-dia. Estão nas telas de televisão, nas telas de cinema, nos cartazes e nas páginas de revistas ilustradas, por exemplo. Segundo Flusser as linhas representam o mundo tridimensional, onde a cartesiana é decisiva para a civilização moderna: ela afirma, resumidamente, que as linhas são discursos de pontos, e que cada ponto é um símbolo de algo que existe lá fora do mundo (um conceito). As linhas, portanto, representam o mundo ao projetá-lo em uma série de sucessões. Desse modo o mundo é representado por linhas, na forma de um processo. Neste meandro o autor divide o estudo das linhas em dois parâmetros: linhas de superfície e linhas escritas.

Nas linhas de superfície podemos apreender a mensagem primeiro e depois decompô-la. Funcionam na segunda dimensão e atuam na história para fora dela. Como exemplo podemos citar os filmes. Já nas linhas escritas precisamos seguir um texto se quisermos captar sua mensagem. Funcionam na primeira dimensão e atuam na história para dentro dela. Como exemplo citamos os textos literários.

\section{As categorias cenopitagóricas de Peirce}

Para Peirce a ideoscopia consiste em descrever e classificar as idéias que pertencem à experiência ordinária ou que emergem naturalmente em conexão com a vida corrente, sem levar em consideração a sua psicologia ou se são válidas ou não-válidas. Deste modo Peirce afirma que todos os elementos da experiência pertencem a três classes em que denominou de categorias cenoptagóricas: primeiro (first), segundo (second) e terceiro (third). Haroldo de campos contribui dizendo que denominou essas três categorias de primariedade, secundariedade e terciaridade.

A primariedade segundo Peirce é a das experiências monádicas ou simples, em que os elementos são de tal natureza que poderiam ser o que são sem inconsistência, ainda que nada mais houvesse na experiência. A secundariedade expressa experiências diádicas ou recorrências, sendo, cada uma, uma experiência direta de um par de objetos em oposição. A terciaridade remete a experiências triádicas ou compreensões; sendo, cada uma, uma experiência direta que liga outras experiências possíveis. Dentro deste contexto, Peirce 
introduz as categorias o seu entendimento por sentimento (feeling) sendo um estado de consciência flagrado em cada um de seus momentos.

Thomas S. Knight, interpretando, epistemologicamente as categorias peirceanas, entende que a primeiridade, referindo-se, a um sentido de qualidade ou a uma idéia de sentimento, seria um estado de consciência sobre o qual pouco pode ser afirmado, a não ser em termos negativos: é incomparável, não-relacional, indiferenciado, impermutável, inanalisável, inexplicável, indescritível, não-intelectual e irracional. Tratando-se de consciência instantânea, é não-cognitivo, original, espontâneo; é um simples sentido de qualidade - o sentido de qualidade de uma cor, por exemplo. Já a secundidade é uma idéia de fato, de luta, de resistência, de poder, de volição, de esforço. Realiza-se ou é percebida nos estados de "choque", surpresa, ação e percepção. Metafisicamente, caracteriza-se pela alteridade, pelo não-ego. [...] A terceiridade não é apenas a consciência de algo, mas também a sua força ou capacidade sancionadora - "o delegado do tribunal de justiça". Sendo cognitiva, torna possível a mediação entre primeiridades e secundidades. Em tudo, sempre haverá algo considerado como começo (primeiro) e algo que pode ser criado como fim (segundo), mas para conhecer a totalidade precisamos conhecer a relação entre começo e fim - o processo (terceiridade). Nas palavras de Peirce: "O modo de ser que consiste no fato de fatos futuros de secundidade virem a adquirir caráter geral, eu chamo de terceiridade".

Segundo Peirce a terceiridade implica generalização e lei - na previsibilidade dos fatos. A lei possui um aspecto compulsivo que se impõe a nós - distinguindo-se, portanto, do simples pensar. São primeiros, portanto, sentimentos e sensações, a indeterminação no mundo físico, qualidades, crenças, artes. São segundos o querer e a volição, a força, os fatos, a dúvida, o mundo dos negócios. São terceiros o conhecer e a cognição, a regularidade estatística no mundo físico, as leis, o hábito, a consciência.

\section{Simulações de programas digitais na visão de Bernard Stiegler}

O autor de "La imagem discreta", Bernard Stiegler, introduz o conceito de imagemobjeto quando trata como o grande acontecimento do século XIX o surgimento da imagem analógica: a fotografia. E ainda comenta que a partir da fotografia, deu-se início a imagem analógica animada (o cinema) como uma extensão da fotografia. 
Ainda, segundo Stiegler, outro grande sucesso em matéria de imagens, surgido no século $\mathrm{XX}$, foi o aparecimento da imagem digital, a que atualmente se denomina de imagens de síntese. Esta sendo um conceito do real que pode imitar quase perfeitamente a realidade. E no final do século XX, o talvez mais completo acontecimento em matéria de evolução de imagens: a imagem analógico-digital que tende a revolucionar a nossa inteligência a respeito do movimento. Desse modo entram em jogo as simulações através de programas digitais na física, química e astrofísica, as simulações na aprendizagem e na ergonomia, nos mundos virtuais, nos clones de seres reais, a inteligência artificial, o reconhecimento de formas, a vida e a morte artificial. Todos estes programas são animações.

Deste modo, o autor, através da análise dos simuladores coloca a técnica de produção digital como momentos de suspensão ou superação, quando por seu desenvolvimento, a técnica atual é interrompida no estado de coisas em função de uma nova, mas atual. Segundo, Stiegler hoje vivemos uma época em que essas características estão mais latentes, em especial no que se refere às imagens e aos sons, sendo denominados como suportes que sustentam a maioria de nossas crenças. Deste modo, através das contribuições de Tomás que diz que cremos no que vemos e escutamos o que percebemos. Neste caminho de análise Stiegler denominou a visão de Tomás como próteses de percepção como forma de percebermos como as imagens e sons nos penetram. E ainda tem a intenção de esclarecer que o significado dos quais constituem nossas crenças ingressaram numa fase de intensa evolução. E a tecnologia analógico-digital é um momento decisivo desta.

\section{O imaginário humano sobre as nouas tecnologias de Erick Felinto}

No livro "A rebelião das máquinas: ensaio sobre o imaginário da cibercultura”, o autor Erick Felinto busca apresentar algumas pistas a respeito das chamadas "novas tecnologia", bem como os instrumentos para uma possível crítica de suas fantasias e do pensamento teórico que por elas se deixa contaminar.

Deste modo, segundo este autor, é natural que a introdução de toda tecnologia em uma cultura produza um dilúvio de expectativas, de insegurança ou otimismo exacerbado. Felinto fala ainda dos momentos iniciais do desenvolvimento das tecnologias da comunicação à distância como o rádio, a televisão e o telégrafo onde não faltaram fantasias e delírios utópicos ou distópicos. Assim, o reitera que se chegou, por vezes, a imaginar que 
tais tecnologias pudessem possibilitar a transmissão de pensamentos à distância de uma mente para outra. Aqui o autor se refere ao ambiente sociocultural de fins da década de 20, Hans Ulrich Gumbrech afirma que "todas essas inovações de rápida difusão nas tecnologias da comunicação, bem como as novas formas de experiência que elas provem, geraram uma atmosfera de fascinação e de otimismo quase sem limites".

No caso das novas tecnologias, segundo Felinto, o vôo da imaginação tem alcançado alturas estratosféricas. Toda tecnologia é "nova" em relação àquela que a precedeu, mas as "tecnologias da Inteligência", como as chama Pierre Lévy (1993), parecem ter a pretensão de serem "novas" de maneira absoluta. Deste modo, seu sentido de novidade radical faz parte das imagens construídas ao redor delas. Segundo Felinto, paradoxalmente, um grande número das representações correntes sobre as novas tecnologias consiste na retomada de antigos mitos, representações arcaicas e anseios primevos. Associadas ao absolutamente novo, essas fantasias ancestrais funcionam como muletas para a aceitação daquilo que apresentaria ser inteiramente incompreensível para nossas limitadas mentes, ao mesmo tempo em que ampliam o poder e fascínio das novas tecnologias. Mais adiante Felinto entra no conceito de ciberespaço onde cita o escritor de literatura científica Willian Gibson como aquele que inaugura o termo em seu romance intitulado Neuromancer, de 1984.

Neste sentido a partir deste contexto Felinto interpreta este ambiente como expressão oriunda do universo sciense fiction vindo a estabelecer-se como noção corrente das interpretações teóricas sobre a natureza das redes de computadores. Mais adiante, Felinto, nos trás as contribuições da proposta de Stefik onde segundo este é preciso mapear alguns dos muitos mitos e símbolos que têm sido utilizados para explicar a nova realidade criada pela internet. Como também das contribuições de Vinton Cerf que afirma que "a internet pode tornar-se qualquer coisa que venhamos a imaginar ou programar. É uma infra-estrutura altamente maleável e envolvente.

O estudo do ciberespaço pode ser encarado, nas palavras de Lemos, como "a encarnação (sic)tecnológica do velho sonho de criação de um mundo paralelo, de uma memória coletiva, do imaginário, dos mitos e símbolos que perseguem o homem". Este autor ainda colabora com esta linha de pensamento dizendo que um dos princípios que os discursos sobre o ciberespaço propagam com insistência, por exemplo, é precisamente a democratização da informação, conceito que entra frontalmente em choque com a natureza 
mesma do discurso hermético, marcado pela "disciplina do arcano", a exigência do segredo e do silêncio.

Felinto aborda ainda que mesmo se as antologias fossem válidas em todos os níveis, ainda teríamos de lidar com dois problemas importantes. O primeiro consiste na ausência de uma perspectiva crítica em relação à proximidade entre projeto tecnológico e imaginário gnóstico. Símbolos e imagens da gnose são utilizados como instrumentos de compreensão do ciberespaço, no pressuposto de que essa aproximação nos ajuda a entender o que realmente é essencial ao fenômeno. Todavia, tais noções não permitem que passemos da lógica paradoxal e intuitiva própria da gnose e do imaginário a uma lógica racional a um conhecimento operativo. Pode-se obter algumas intuições sobre a natureza do imaginário tecnológico, mas não um conhecimento efetivamente teórico e crítico a respeito daquilo que a tecnologia poderá representar em termos culturais, econômicos e sociais. O segundo problema consiste em uma cilada epistemológica: o uso da analogia pura e simples aprisiona a argumentação na estrutura característica da forma mentis utilizada como um dos termos da comparação. Emprega-se, como instrumento epistemológico, a ferramenta tradicional do próprio objeto de comparação, a gnose, em uma espécie de círculo vicioso. O pensamento analógico é o grande traço da mentalidade hermética, como enuncia o famoso dito da tábua esmeralda de Hermes Trismegisto, "o que está em cima é como o que está embaixo". O valor da analogia como instrumento de conhecimento não PE desprezível, mas quando o pensamento limita-se a trabalhar comparativamente, corre-se o risco de esquecer a importância do diferencial histórico. Comparam-se fenômenos distantes no tempo e/ou no espaço, buscando encontrar semelhanças em cada detalhe e esquecendo, assim, a singularidade histórico-cultural peculiar a cada fenômeno.

\section{Elementos sensíuel/inteligíuel e significado/significante segundo análise de Siluiano}

\section{Santiago}

No livro "Uma literatura nos trópicos: ensaios sobre dependência cultural", o autor Silviano Santiago propõe configurar três momentos e modos distintos de pesquisa em Teoria da Literatura, orientado segundo alguns estudiosos franceses da última década.

Dentro deste contexto, para Lévi-Strauss (como para Ganette), o universo instrumental do bricoleur (como o do crítico literário) é, por definição, "fechado", e "a regra do seu jogo é a de sempre se virar com os meios de bordo”. Temos aqui a diferença 
entre o objeto natural e o simulacro, que se expressa pela passagem de um conjunto instrumental dado a um conjunto a se realizar, sendo que a diferença entre eles vai ser instaurada pela disposição interna das partes. Tal semelhança (de instrumento) e tal diferença (de disposição interna), circunscritas ambas ao mesmo, se explicam pelo duplo estatuto que cada elemento do conjunto instrumental comporta em si: cada um é ao mesmo tempo concreto e virtual. Situa-se cada um deles a meio-caminho entre o "preceito" (percept) e o "conceito" (concept).

A partir daí Santiago entra na questão que envolve o simulacro dizendo que quanto na atividade descrita como bricolage, tratava-se de levantar os vários elementos significativos e constituintes do objeto "natural", e dar a esses elementos um duplo estatuto (sensível e inteligível; significante e significado), e com isso, pô-los em movimento, analisando mecanismos internos das funções ou o jogo relacional entre os elementos no interior do objeto. Mas é importante salientar que nos dois casos a visada era bem mais audaciosa do que parecia: o fim da atividade estruturalista era o todo. O todo na medida em que era artificialmente fechado como "sensível" e/ou "inteligível", como "objeto natural" e/ou "simulacro" no pensamento de Barthes. O todo, enquanto fechado ("conjunto finito") na arquitetura teórica do bricoleur, tal qual foi definida no pensamento do primeiro Lévi-Strauss. Em suma, a análise perfazia o mesmo caminho do objeto, apenas usando atalhos suspeitos. São os chamados atalhos do conceito e da razão, e que conduziam a atividade analítica a querer açambarcar a "solidariedade" dos elementos internos, ou a "totalidade" do objeto estudado.

Sobre este ponto de vista o tipo de análise descrita anteriormente até o momento foi realizado seguindo posteriormente duas postulações teóricas. Ou bem o processo de reconstituição era feito a partir de um exemplo único e se apresentava o estudo deste exemplo como matriz teórica para a análise de outros exemplos semelhantes aproveitandose a lição teórica e clássica da poética, de Aristóteles. Ou bem se estabelecia a priori um modelo de análise teórico, baseando-se para isso principalmente nos ensinamentos, já julgados "científicos" da lingüística, e em seguida os divulgadores ficavam com a tarefa de aplicá-los aos mais variados objetos.

Em relação a isso, o autor informa que em ambas as atitudes descritas acima, encontramos o desejo de só estudar um exemplo, ou ainda, quando a análise se atinha a um corpus mais amplo (como no caso de Propp, ou do Barthes na análise narrativa) era apenas 
para assinalar e enxergar nos exemplos múltiplos aquilo que os reduzia teoricamente (isto é, no laboratório de análise) a um mesmo modelo.

Segundo o autor aqueles dois tipos de análise poderíamos chamar, no campo propriamente literário, de leitura opaca, na medida em que a exemplificação se atém ao fechamento do texto, ou dos textos estudados, não procurando enxergá-los ou compreendêlos na sua diferença. Tinham a diferença como conceito semântico, mas não a tinham como conceito operacional. E, é claro, ainda não tinham a differénce, que é o momento anterior a toda diferenciação, a toda a conceituação binária, ante-cena, portanto da metafísica ocidental. Tinham o jogo e a relação como inspiradores do significado a ser depreendido do texto, mas não os tinham como elementos estruturantes. O jogo e a relação se esgotavam no centramento operado pela reconstituição totalitária, pelo movimento de agencement, na sua tentativa de configurar a solidariedade de configurar todos os objetos "natural", de configurar o que Barthes chamava de "simulacro". Portanto, não tinham, ainda, é claro, como preocupação maior a organização desses objetos naturais dentro de uma determinada ordem que escapasse às da semelhança e da oposição, proporcionada pela visão sincrônica (a-histórica) ou dada de presente pelo modelo teórico utilizado.

No segundo tópico Santiago fala do caráter teórico-especulativo, onde torna necessário repensar o esquema de análise que, didática e apressadamente, descrevemos anteriormente. As razões empíricas podem ser exemplificadas pelo fato de que o analista tivesse sentido a necessidade de explicar aquilo que tradicionalmente se chamava a "obra completa" de um escritor, isto é, um conjunto de textos que têm algo em comum, mas que se exprime, no momento em que a análise em separado é abandonada, como diferença. Necessidade ainda de explicar o que, dentro da modernidade, se convencionou chamar "texto de apropriação", ou seja, texto que, para a sua leitura exemplar, nos remete a outro (s) texto(s), texto que deixa ver em sua transparência outros textos.

Corroborando com isso, Santiago reitera que tanto no caso da "obra completa" de um escritor, como no dos poemas de apropriação, era necessário começar a pensar conceitos até então impensados pelo estruturalismo, ou de maneira mais ampla, conceitos que "solicitaria" (abalariam o todo, etimologicamente) o edifício da metafísica ocidental. Mas faltava aos teóricos, seja a base filosófica, seja a coragem para sair desse campo teórico cujo estatuto se definia pela "cientificidade" do método utilizado, o lingüístico, e realmente questionar a teoria enquanto problemática se desenvolvendo dentro (e fora) de uma maneira de pensar, ou de ler, que era o pensamento ocidental. 
Consequentemente surge pelo menos três conceitos se infiltravam na atividade estruturalista, fazendo com que de maneira inocente (perceber-se-ia mais tarde) se começasse a escrever o fechamento da metafísica ocidental: a diferença, a transgressão e a contradição.

Pela diferençam começa-se a pensar a instância de articulação de um texto sobre outro(s). Não mais são considerados os textos isoladamente, ou como pertencentes a um único modelo do mesmo, mas como se diferenciando na repetição, como um diálogo entre um mesmo e um outro. Recoloca-se, portanto a problemática do "sujeito" (do "autor", em termos literários), por não existe uma origem clara e altissonante que se deve buscar no processo de exemplificação do texto, origem também da verdade deste texto e que se aclara no processo de análise literária.

E, ainda nesse âmbito de análise, quando da inserção se inscrevia num espaço que dramatizava o choque entre duas culturas (a européia e a indígena, por exemplo), se descobre um processo de transgressão aos valores de uma das culturas, a cultura dominante no caso. Tal se passa, ainda, no mesmo exemplo, quando percebemos que o questionamento básico dos poemas de Oswald são os dos valores da cultura portuguesa, ocidental e cristã, espraiados desde a Carta para os outros discursos que representam de maneira similar a terra brasileira.

Finalizando este parâmetro de estudo, Santiago conclui os três expoentes de pensamento em que coloca a afirmação e a negação, a contradição se afirma pela diferença (e não por uma simples síntese), ela existe como conceito operacional, pois é ela que pode dar conta deste criar pela destruição, deste destruir pela criação, que mais e mais significa (estamos descobrindo um pouco tarde) o espírito moderno.

Assim, sendo mais adiante o autor vai falar que a interpretação sempre se volta sobre si mesma, criando este movimento de circularidade que será então definidor do movimento do conhecimento humano.

E ainda conclui dizendo que a partir do momento em que postulou essas idéias, foi importante para Derrida a releitura crítica do Fedro, de Platão, texto onde colocava de maneira clara a condição assassina da escritura. O "pai" se ausenta no momento em que escreve e sem a presença paterna o discurso escrito, como diz sem a presença paterna o discurso escrito, como diz Sócrates a Lísias, "necessita sempre a ajuda de seu pai, uma vez que não é capaz de se defender e socorrer a si mesmo". 
Portanto, escrever é, pois, cair longe da sua linguagem, emancipá-la, ou desamparála, deixá-la caminhar sozinha e desmunida. Abandonar a palavra... deixá-la falar sozinha, o que ela só pode fazer escrevendo.

\section{Referências Bibliográficas}

BENJAMIM, Walter. A obra de arte na era da sua reprodutibilidade técnica. In: Magia e técnica, arte e política. São Paulo: Cosac Naify, 2007.

FELINTO, Erick. Por uma crítica do imaginário tecnológico: novas tecnologias e imagens da transcendência. In: __ A rebelião das máquinas, ensaios sobre o imaginário e a cibercultura. Porto alegre: Sulina, 2006. P. 53-70.

FLUSSER, Vilém. Códigos. In: $O$ mundo codificado: por uma filosofia do design e da comunicação. São Paulo: Cosac Naify, 2007.

LÈVY, Pierre. O que é o virtual. São Paulo: Ed 34, 1996.

PARENTE, André. O virtual e o hipertextual. Rio de Janeiro: Pazulin, 1999. P. 13-45.

PIGNATARI, Décio. Semiótica e literatura. 6a. Ed. São Paulo: Ateliê Editorial, 2004. P. 39-83.

SANTIAGO, Silviano. "Análise e interpretação". In: Tempo Brasileiro, n 41. Rio de Janeiro, abril-junho de 1975, p. 8-22.

STIEGLER, Bernard. La imagem discreta. In: DERRIDA, Jaques. Ecografias de la televisión. Entrevistas filmadas a Bernard Stiegler. Buenos Aires: Eudeba, 1998. 